\title{
Circulating Sex Steroids and Breast Cancer Risk in Premenopausal Women
}

\author{
Susan E. Hankinson • A. Heather Eliassen
}

Received: 20 October 2009 /Accepted: 17 December 2009/Published online: 9 February 2010

(C) Springer Science+Business Media, LLC 2010

\begin{abstract}
Evidence from both laboratory and epidemiologic studies indicate a key role of hormones in the etiology of breast cancer. In epidemiologic studies, indirect data, including the consistent associations observed between reproductive factors and breast cancer risk, support an important contribution of hormones to risk. Recently, the associations between circulating hormones in premenopausal women and subsequent risk of breast cancer have been evaluated. To date, both positive and null associations have been observed for estrogens and inverse and null associations for progesterone with breast cancer risk. For estrogens, the relationships may vary by menstrual cycle phase (e.g., follicular versus luteal phase), although this requires confirmation. Few studies have evaluated estrogen metabolites in relation to breast cancer risk; hence, no conclusions can yet be drawn. Findings for the largely adrenal-derived dehydroepiandrosterone (DHEA) and DHEA sulfate also are inconsistent and may vary by age. However, relatively consistent positive associations have been observed between testosterone (or free testosterone) levels and breast cancer risk; these associations are of similar magnitude to those confirmed among postmenopausal women. In this review, we summarize current evidence and identify gaps and inconsistencies that need to be addressed in future studies of sex steroids and premenopausal breast cancer risk.
\end{abstract}

S. E. Hankinson $(\square) \cdot$ A. H. Eliassen

Channing Laboratory, Department of Medicine,

Harvard Medical School and Brigham and Women's Hospital,

181 Longwood Avenue,

Boston, MA 02115, USA

e-mail: sue.hankinson@channing.harvard.edu

S. E. Hankinson · A. H. Eliassen

Department of Epidemiology, Harvard School of Public Health, Boston, MA 02115, USA
Keywords Prospective - Estrogens · Androgens . Progesterone $\cdot$ Breast cancer $\cdot$ Premenopausal

Over the last decade, the association between circulating sex steroid concentrations, both estrogens and androgens, and risk of breast cancer in postmenopausal women has become well established. Postmenopausal women in the top $25 \%$ of estrogen or androgen levels have a 2 - to 3 -fold higher risk of being diagnosed with breast cancer than women in the lowest $25 \%$ of levels [1-3]. Because of these consistent associations, research is now being directed towards determining if circulating hormone levels could be used clinically to help determine a postmenopausal woman's individual risk of breast cancer and could help direct the frequency of mammographic screening or use of chemopreventive agents. However, what is the status of research on circulating sex steroid levels and breast cancer risk in premenopausal women? Are similar positive associations observed? An overview of our current understanding of these relationships is provided in the current review.

The critical role of hormones in the etiology of premenopausal breast cancer is well confirmed from both laboratory and human data [4-7]. Evidence from epidemiologic studies supporting a hormonal etiology includes the consistent associations observed between several hormonally related risk factors and breast cancer (Table 1) [4, 8]. Nulliparous women and women having a late age at first birth (e.g., $>35$ years) have a higher breast cancer risk than parous women or those with an early age at first birth, respectively. An early age at menarche, and therefore earlier exposure to reproductive hormones, is associated with an increased risk of breast cancer. Further, in premenopausal women, obesity is associated with lower breast cancer risk, 
Table 1 Established hormone-related risk factors for premenopausal breast cancer

\begin{tabular}{ll}
\hline Risk factor & Higher risk group \\
\hline Age at menarche & Early age at menarche \\
Age at first birth & Later age at first birth \\
Parity & Nulliparous or fewer children ${ }^{\mathrm{a}}$ \\
$\begin{array}{l}\text { Premenopausal body mass } \\
\text { index }\left(\mathrm{kg} / \mathrm{m}^{2}\right)\end{array}$ & Low body mass index \\
Childhood body size & Small body size/lean \\
Breast feeding & No breast feeding (or shorter durations) \\
Mammographic density & Higher density \\
\hline
\end{tabular}

${ }^{a}$ Parity infers a short term $(<1$ decade) increase in risk, followed by a long-term decrease in risk

References: Hankinson SE et al. 2004 4. Breast Cancer Res: 6(5): 213-218; de Waard F, Thijssen JH. 2005 8. J Steroid Biochem Mol Biol: 97(5): 451-458

perhaps due to increased anovulatory cycles. Also, tamoxifen, a selective estrogen receptor modulator, reduces breast cancer incidence $[9,10]$ and is used in breast cancer treatment [11].

This review will focus primarily on data from prospective studies. In these studies, hormone levels are measured prior to breast cancer diagnosis and hence are less susceptible to bias than are retrospective case-control studies. In retrospective case-control studies, hormone levels in the women with breast cancer may be influenced either by the tumor or its treatment and hence may not reflect prediagnostic levels. First, we discuss several methodologic issues that are relevant in interpreting the results of these prospective studies.

\section{Methodologic Issues}

In most epidemiologic studies, for both logistic and cost reasons, usually, only a single blood sample can be collected per study subject. Hence, an important issue is whether a single blood hormone measure can reasonably reflect long-term hormone levels in premenopausal women (as long-term hormone levels are the exposure of primary interest in etiologic studies of breast cancer). To address this, several studies have evaluated the correlation in hormone levels from samples collected repeatedly over a several-year period from premenopausal women.

For testosterone measured over a 1-3 year period, intraclass correlation coefficients (ICC; the ratio of the between person variation/[the between + within person variation]) ranged from $0.56-0.73$ [12-14], for both timed (e.g., follicular or luteal phase) and untimed samples. For dehydroepiandrosterone (DHEA) and DHEA sulfate (DHEAS), androgens derived primarily from the adrenals, the ICC over the same period of time were even higher, ranging from $0.81-0.95[12,14]$.

Estrogens, particularly estradiol, vary substantially over the menstrual cycle such that a single blood sample would not well represent an entire menstrual cycle. However, several studies have assessed how well a single hormone measurement from a specific phase of the menstrual cycle (i.e., follicular or luteal) might be representative of longterm levels in that phase. In the only large study to date ( $n=$ 113 women), the ICC over a 2-3 year period for estradiol was 0.38 in the follicular phase and 0.45 in the luteal phase; the luteal phase ICC increased to 0.51 when samples collected in an anovulatory cycle were excluded. The ICC for estrone was similar, while the ICC for estrone sulfate was higher $(0.60-0.69)$. When women who are anovulatory in at least one cycle or missed their luteal phase are not excluded from these types of analysis, the ICC can be very low (e.g., $<0.1[12,15]$ ) depending on the prevalence of these two factors. Notably, the ICC over time for estradiol when combining follicular and luteal samples (i.e., disregarding cycle phase) was just 0.02 [14] indicating that samples untimed in the menstrual cycle would not be able to distinguish between woman differences in hormone levels and hence are not usable for epidemiologic studies. Progesterone also varies substantially over the menstrual cycle. The ICC for luteal phase progesterone has been reported at 0.29 [14] to 0.54 [15] over a $1-3$ year period.

Using a single blood sample in epidemiologic studies to represent long-term hormone levels undoubtedly results in some attenuation of relative risk estimates. The level of reproducibility noted above for androgens and estrone sulfate, and to a lesser extent estradiol, estrone, and progesterone, is similar to that of blood pressure or serum cholesterol (where ICCs over a several-year period are 0.60.7 ), parameters that are reasonably measured and consistent predictors of disease in epidemiologic studies [16]. For assessment of estrogen levels, given the poor ICCs for estrogens when menstrual timing is disregarded, it is critical to account for timing within the menstrual cycle either in the study design or data analysis. In contrast, the androgens vary much less markedly over the menstrual cycle (relative to the between woman variation in levels), and hence, timing the blood collection is not required [14]. Given the lower ICC for estradiol and progesterone, correction of relative risks for measurement error would provide additional insight into the underlying true association between hormones and risk, as risk estimates for hormones with lower ICCs are likely underestimated [17].

In epidemiologic studies, circulating hormone levels are most often measured because blood samples are relatively easy to obtain and can be readily used for risk screening. Yet, relatively little is known about how circulating levels correlate with exposure in the breast tissue. Only two 
studies have presented the correlation between circulating hormone levels and breast tissue levels. In the first, 22 premenopausal women (16 with breast cancer and six with benign breast disease) were included and the correlation between tumor tissue hormone levels and blood hormone levels assessed [18]. The correlation for estrone was 0.52 in the follicular phase and 0.63 in the luteal phase. For testosterone, the correlation was 0.64 in the follicular phase and -0.51 in the luteal phase; why the correlation in the follicular phase was strongly positive and that in the luteal phase strongly inverse is not clear and requires confirmation. Only one study has presented correlations between non-malignant breast tissue levels and blood levels, collected from 13 premenopausal women with breast cancer [19]. The correlation was 0.69 for estradiol, estrone, and estrone sulfate; correlations were not reported separately by menstrual cycle phase. Thus, although data remain scarce, to date results suggest some correlation between circulating levels and tissue levels in premenopausal women.

\section{Sex Steroids and Breast Cancer Risk}

\section{Estrogens and Estrogen Metabolites}

Mechanistically, estrogens (e.g., estradiol and estrone) contribute to tumor growth by promoting the proliferation of cells with existing mutations or perhaps by increasing the opportunity for mutations [20]. Although most research has focused on the primary (or parent) estrogens, increasing interest has also focused on the metabolites of estrogen. The metabolism of estrone and estradiol occurs through different pathways, including the 2-, 4-, and $16 \alpha-$ hydroxylation pathways, and experimental studies have shown that estrogen metabolites may have differential estrogenic and genotoxic activities [21, 22]. For example, the metabolites in the $4-$ and $16 \alpha$-hydroxylation pathways may have higher estrogenic activity than estradiol [23-29] while 2-catechol estrogen metabolites may act as either weak mitogens $[30,31]$ or inhibitors of proliferation [32, 33]. In addition, DNA damage may vary by metabolite, e. g., the 2-catechol estrogen quinones form stable DNA adducts that are reversible without DNA destruction [3436], while the 4-catechol estrogen quinones form unstable adducts, leading to depurination and mutation in vitro and in vivo $[35,37-40]$. Thus, the specific pattern of estrogen metabolism has been hypothesized to influence a woman's breast cancer risk, either through estrogen receptormediated cell proliferation or through genotoxic effects of the metabolites.

Seven prospective studies of circulating estrogens (i.e., estradiol, estrone, and estrone sulfate) in premenopausal women and risk of breast cancer have been published to date. Three of the studies were very small (14-51 cases [41-43]) or did not account for menstrual cycle phase [43]; no significant association with estradiol was noted, although because of study size, precision of the estimates was uniformly low. In two other studies (with 62 and 79 cases) where timing of the blood collection was carefully accounted for, non-significant positive associations were reported (relative risks for the top versus bottom tertile of estradiol levels: 1.7 for both follicular and luteal estradiol levels and risk [44] and 2.0 [95\% CI $0.9-4.0]$ over the entire menstrual cycle [45]).

Two much larger studies have also addressed these associations. In the largest study to date, conducted in the EPIC cohort, with 285 invasive breast cancer cases and 555 controls, a single blood sample was collected per woman, and the day of collection within the menstrual cycle was recorded [46]. Controls were matched to cases on age, study center, time-of-day of collection, and phase of the menstrual cycle at blood collection (in five categories). Comparisons between case and control hormone levels were based on residuals from spline regression models; the residuals indicated how much an individual's hormone level deviated from the predicted hormone levels on that day of the menstrual cycle. Overall, no association was observed for either estradiol or estrone (top to bottom quartile comparison $R R=$ $1.0[95 \% \mathrm{CI}=0.7-1.5]$ for estradiol; Table 2). Of note, because blood samples were collected across the menstrual cycle, the investigators had relatively limited ability to evaluate associations within specific parts of the cycle.

In the second large prospective study [47], conducted within the Nurses' Health Study II (NHSII), both early follicular (days 3-5) and mid-luteal (estimated 7-9 days prior to next cycle) samples were requested from each woman. Timing of the luteal sample collection was by backward dating from the onset of the next menstrual cycle. The analysis included 197 cases (in situ and invasive combined) with 394 controls matched on age, menopausal status at diagnosis, ethnicity, luteal day, date and time of blood draw, and fasting status. Follicular, but not luteal, total and free estradiol was significantly associated with breast cancer risk (top to bottom quartile comparison $R R=2.1[95 \% \mathrm{CI}=1.1-4.1]$ for follicular total estradiol; Table 2). Associations were stronger among the 89 estrogen receptor positive $(\mathrm{ER}+)$ /progesterone receptor positive $(\mathrm{PR}+)$ cases (similar comparison $R R=$ $2.7[95 \% \mathrm{CI}=1.2-6.0]$ for follicular total estradiol), supporting the biologic hypothesis that estrogens stimulate ER + tumors. No association was observed with either estrone or estrone sulfate (in either the follicular or luteal phase of the cycle).

Interestingly, in this study, follicular, and not luteal, estradiol levels were positively associated with risk. Although these initial findings require confirmation, several possible reasons exist for these differences. A greater 
Table 2 Circulating levels of estradiol, testosterone, and DHEAS in relation to premenopausal breast cancer risk

$R R(95 \% \mathrm{CI})$ by category of circulating hormone levels ${ }^{\mathrm{a}, \mathrm{b}}$

\begin{tabular}{|c|c|c|c|c|c|c|}
\hline Study & Cases/controls & 1 (low) & 2 & 3 & 4 (high) & $p$ trend \\
\hline \multicolumn{7}{|l|}{ Estradiol } \\
\hline Rosenberg et al., 1994 [45] & $79 / 306$ & 1.0 & $1.8(1.0-3.7)$ & $2.0(0.9-4.0)$ & & 0.18 \\
\hline Kaaks et al. 2005 [46] & $285 / 555$ & 1.0 & $1.0(0.6-1.5)$ & $1.0(0.7-1.6)$ & $1.0(0.7-1.5)$ & 0.89 \\
\hline \multicolumn{7}{|l|}{ Eliassen et al. 2006 [47] } \\
\hline Follicular & $185 / 368$ & 1.0 & $2.0(1.1-3.6)$ & $1.7(1.0-3.2)$ & $2.1(1.1-4.1)$ & 0.08 \\
\hline Luteal & $175 / 349$ & 1.0 & $1.2(0.7-2.3)$ & $1.8(1.0-3.3)$ & $1.0(0.5-1.9)$ & 0.99 \\
\hline \multicolumn{7}{|l|}{ Testosterone } \\
\hline Micheli et al. 2004 [63] & $40 / 108$ & 1.0 & $1.1(0.4-3.0)$ & $2.2(0.6-7.6)$ & & 0.28 \\
\hline Kaaks et al. 2005 [46] & $370 / 726$ & 1.0 & $1.4(1.0-2.1)$ & $1.4(0.9-2.0)$ & $1.7(1.2-2.6)$ & 0.01 \\
\hline \multicolumn{7}{|l|}{ Eliassen et al. 2006 [47] } \\
\hline Follicular & $190 / 374$ & 1.0 & $1.3(0.8-2.2)$ & $1.4(0.8-2.3)$ & $1.3(0.8-2.4)$ & 0.35 \\
\hline Luteal & $192 / 390$ & 1.0 & $1.3(08-2.3)$ & $1.4(0.8-2.3)$ & $1.6(0.9-2.8)$ & 0.10 \\
\hline \multicolumn{7}{|l|}{ DHEAS } \\
\hline Helzlsouer et al. 1992 [65] & $15 / 29$ & 1.0 & $1.4(0.7-6.4)$ & $1.2(0.2-6.3)$ & & 0.90 \\
\hline Micheli et al. 2004 [63] & $65 / 260$ & 1.0 & $0.9(0.3-2.6)$ & $1.2(0.4-3.3)$ & & 0.76 \\
\hline \multirow[t]{2}{*}{ Page et al. 2004 [66] } & $302 / 591^{\mathrm{c}}$ & 1.0 & $1.3(0.8-1.9)$ & $1.3(0.9-2.0)$ & $1.1(0.7-1.7)$ & 0.83 \\
\hline & $101 / 197^{\mathrm{c}}$ & 1.0 & $1.5(0.7-3.4)$ & $1.5(0.7-3.4)$ & $1.5(0.7-3.3)$ & 0.62 \\
\hline Kaaks et al. 2005 [46] & $370 / 726$ & 1.0 & $1.4(1.0-2.0)$ & $1.0(0.7-1.5)$ & $1.5(1.0-2.1)$ & 0.10 \\
\hline Tworoger et al. 2006 [67] & $208 / 421$ & 1.0 & $0.7(0.4-1.2)$ & $1.1(0.6-1.8)$ & $1.3(0.8-2.1)$ & 0.08 \\
\hline
\end{tabular}

${ }^{\text {a }}$ Studies included in Table 2 provided relative risks $(R R)$ within categories of hormone levels in the original publication. Other studies (four for estradiol, two for testosterone) provided either no $R R, R R$ for 1-log-unit increase in hormone levels, or $R R$ for levels above vs. below median; these studies are discussed in the text

${ }^{\mathrm{b}}$ Hormone data presented in quartile or tertile categories depending on the study

c 302/591 subjects premenopausal at blood collection; 101/197 subjects premenopausal at both blood collection and cancer diagnosis

proportion of early follicular estradiol levels (vs. luteal levels) derives from non-ovarian sources [47-49] and thus may better reflect estrogen levels at the breast tissue. Another possibility is that the follicular phase might be a more relevant period of exposure, given that women in later premenopause, as were included in this study, have longer follicular and slightly shorter luteal phases [50, 51]. Alternatively, estradiol might be more important in the low-progesterone environment of the follicular phase. Breast tissue concentrates estradiol to a greater degree at lower circulating levels, such as in the follicular phase [52, 53]. In addition, apoptosis in lobuloalveolar cells may be higher in the luteal versus the follicular phase [54], such that the proliferative effects of high estrogen levels in the luteal phase may be offset by increased apoptosis.

To date, there have been only three prospective studies to evaluate estrogen metabolites and breast cancer risk among premenopausal women, and these studies only have included the 2-hydroxyestrone and 16 $\alpha$-hydroxyestrone metabolites. Two studies of fewer than 70 cases each examined the 2hydroxyestrone $/ 16 \alpha$-hydroxyestrone ratio in urine $[55,56]$. In the Guernsey III cohort, with cases and controls matched on menstrual cycle phase (follicular or luteal), a non-significant reduced risk of breast cancer was observed among women in the highest vs. lowest tertile of the 2-hydroxyestrone/16 $\alpha$ hydroxyestrone ratio, $R R(95 \% \mathrm{CI})=0.75(0.35-1.62)$ [55]. In the Italian ORDET study, with urine samples collected in the luteal phase of the menstrual cycle (days 20-24), a non-significant inverse association was reported for the 2-hydroxyestrone/16 $\alpha$-hydroxyestrone ratio, $R R(95 \%$ CI) for top vs. bottom quintile $=0.55(0.23-1.32)$ [56].

The most recent and largest study of estrogen metabolites and breast cancer in premenopausal women, in the NYU study, assessed serum 2-hydroxyestrone and 16 $\alpha$ hydroxyestrone [57]. With 377 cases matched to controls on day and phase of the menstrual cycle, no significant associations were found overall with either metabolite or the 2-hydroxyestrone/16 $\alpha$-hydroxyestrone ratio. However, when examining ER + and ER- cases separately, a nonsignificant increased risk of ER + breast cancer was observed with higher 2-hydroxyestrone/16 $\alpha$-hydroxyestrone ratios, $R R(95 \% \mathrm{CI})$ for top vs. bottom quartile= 2.15 (0.88-5.27).

To date, no studies have evaluated the role of other estrogen metabolites in the etiology of breast cancer in premenopausal women. It is possible that other metabolites 
are important either individually, e.g., 4-hydroxy estrogens or methylated catechols, or with respect to the particular pattern of metabolism within individuals, e.g., greater proportion of methylated vs. catechol metabolites. A highperformance liquid chromatography-tandem mass spectrometry $\left(\mathrm{LC}-\mathrm{MS}^{2}\right)$ assay was developed recently to measure concurrently 15 estrogens and estrogen metabolites in urine with high sensitivity, specificity, accuracy, and reproducibility $[58,59]$. Reproducibility of these estrogen metabolites within woman over time suggests that the metabolites are suitable for epidemiologic study (e.g., ICC for luteal phase catechols, methylated catechols, and the catechol/methylated catechol ratio were $0.72,0.61$, and 0.60 , respectively) [60]. In addition, the correlation between the parent estrogens and their metabolites was fairly low (e.g., estrone and estradiol correlations with other individual estrogen metabolites was $\leq 0.52$ ), suggesting that these estrogen metabolites may provide additional information that may be important in the etiology of breast cancer.

\section{Androgens}

Androgens have been hypothesized to increase breast cancer risk either directly, by increasing cellular growth and proliferation, or indirectly, by their conversion to estrogen [5]. In experimental studies, androgens either increase or decrease cell proliferation, depending upon the model system [5]. The effect of adrenal androgens, such as dehydroepiandrosterone (DHEA) or its sulfate, on breast cancer risk has further been hypothesized to depend on estrogen levels, such that before menopause, DHEA/S exhibit anti-estrogenic effects, but after menopause they are weakly estrogenic [61, 62].

\section{Testosterone}

As with estrogens, few prospective studies have evaluated the association between circulating testosterone and risk of breast cancer in premenopausal women. Of the five prospective studies published to date, three were small with 17 [41], 40-65 [63] (depending on the analysis), and 65 [44] cases, respectively, and again, confidence intervals were wide. In two of the studies [41, 44], no association was observed while in the third [63], significant positive associations were observed for free testosterone (top vs. bottom tertile $R R=2.9[95 \% \mathrm{CI}=1.1-7.3]$ ) and nonsignificant positive associations observed for total testosterone (Table 2).

In the large EPIC cohort, with 370 invasive breast cancer cases and 726 controls, significant positive associations were observed between circulating levels of testosterone and risk of breast cancer [46]. The $R R \mathrm{~s}(95 \% \mathrm{CI})$ with increasing testosterone level (in quartile categories) were 1.0, 1.4
$(1.0-2.1), 1.4(0.9-2.0)$, and $1.7(1.2-2.6)(p$ trend $=0.01$; Table 2).

In the NHSII, with 197 cases (including both in situ and invasive disease) and 394 controls, modest, but not statistically significant, positive associations were observed for testosterone (in both the follicular and luteal phase); the associations, particularly for follicular testosterone, did not appear entirely linear [47]. The associations were stronger and statistically significant when restricting to invasive (i.e., using a comparable case group to that in the EPIC study) or $\mathrm{ER}+/ \mathrm{PR}+$ tumors. In the luteal phase, for invasive cancers, relative risks increased with increasing quartile category of levels ( $R R$ from lowest to highest quartile $[95 \% \mathrm{CI}] 1.0$, $1.6,1.3,2.0[1.1-3.6] ; p$ trend $=0.05$ ); similar findings were observed among the subset of invasive $\mathrm{ER}+\mathrm{PR}+$ tumors (comparable $R R$ s 1.0, 2.3, 1.4, $2.9[1.4-6.0] ; p$ trend $=0.02$ ). Findings for free testosterone generally mirrored those for total testosterone. Thus, cumulatively, studies are quite consistent in finding a significant positive association between testosterone levels and risk of invasive breast cancer in premenopausal women.

\section{Dehydroepiandrosterone and DHEA Sulfate}

A positive association between DHEA/S and breast cancer risk has been observed consistently in postmenopausal women [13, 64]. Among premenopausal women, five prospective studies have been published to date. Two of the studies were small, with 15 and 40 cases, and no significant associations were noted [63, 65]. Among premenopausal women in the Nurses' Health Study, no association was observed overall for either DHEA or DHEAS [66]. Among the subset of women who were premenopausal at both blood collection and at diagnosis, a non-significant positive association was reported (top vs. bottom quartile $R R=1.5(95 \% \mathrm{CI}=0.7-3.3)$; Table 2). In the large EPIC cohort, a modest but statistically significant positive association was observed comparing the top $20 \%$ of DHEAS levels to the bottom $20 \%(R R=1.5 ; 95 \%$ CI 1.0-2.1) although the trend over hormone categories was not statistically significant ( $p$ trend $=0.10)[46]$. In the only other large study (NHSII), no overall association was observed with DHEA/S - relative risks comparing top vs. bottom quartiles were 1.0 (DHEA) and 1.3 (DHEAS) and not statistically significant [67]. The associations were somewhat stronger among ER+ cases only (top vs. bottom quartile for DHEA $=1.6[95 \% \mathrm{CI}=0.9-2.8]$ and DHEAS $=1.9[95 \%$ $\mathrm{CI}=1.1-3.2]$ ), although, in this analysis, only $75-80 \%$ of the women were premenopausal. A significant interaction was noted with age ( $p$ for heterogeneity $<0.05$ ). Specifically, a non-significant inverse association was observed among premenopausal women $<45$ years old at blood collection and significant positive associations among those $\geq 45$ years for both hormones (e.g., top vs. bottom quartile $R R(95 \% \mathrm{CI})$ for 
DHEAS: $\quad<45 \mathrm{yrs}=0.6(0.3-1.3) ; \geq 45 \mathrm{yrs}=2.5(1.1-$ $5.5)$ ). This variation in associations by age was not observed in the EPIC cohort however. The data linking either DHEA to DHEAS to breast cancer risk in premenopausal women has not been consistent, and overall, no substantial association has been observed.

\section{Progesterone}

Progesterone has strong influences on breast physiology. It has been hypothesized to either decrease breast cancer risk, by mitigating the estrogen-induced proliferation in breast epithelial cells $[68,69]$, or increase risk due to the higher breast cell proliferation in the luteal phase when progesterone levels are the highest [70]. Depending on the model system, evidence from animal and in vitro studies supports each of these hypotheses [71, 72]. In epidemiologic studies of postmenopausal hormone use, breast cancer risk is well confirmed to increase more with use of postmenopausal estrogen plus progestin than with use of postmenopausal estrogens alone [73-76].

To date, only six prospective studies have examined circulating progesterone levels and breast cancer risk in premenopausal women, with four of the six studies including 65 or fewer cases [41, 42, 44, 63]. Nonsignificant inverse associations were observed in three of the smaller studies [41, 44, 63], and a non-significant positive association was observed in the fourth [42].

In the large EPIC cohort study, with 285 cases and 555 controls, a significant inverse association was observed between progesterone levels (residuals from spline regression model) and breast cancer risk (top to bottom quartile comparison $R R=0.6[95 \% \mathrm{CI} 0.4-1.0]$ ) [46]. This association was driven by women with samples drawn in the luteal phase and was only apparent among cases and controls matched by forward dating, not among those matched by the more accurate backward dating approach. In the second large study, utilizing backward dating with 197 cases and 394 controls, no association was observed between luteal progesterone levels and risk [47]. Given the limited number of studies to date and the complexities of measuring progesterone during the menstrual cycle (and resultant lower ICC observed as noted above), the relationship of circulating progesterone levels to breast cancer risk remains unknown.

\section{Conclusion}

In contrast to the rapidly accumulating data in postmenopausal women, relatively few studies on circulating sex steroids levels and breast cancer have been conducted in premenopausal women. This is largely due to the variation in hormone levels, particularly estradiol and progesterone levels, over the menstrual cycle thus making epidemiologic studies (that routinely depend on collecting a single blood sample from each study subject) particularly complex. However, several studies have shown these methods to be feasible and valid, although nesting in substudies that allow measurement error correction of relative risk estimates is desirable.

The only consistent finding to date is a positive association between testosterone levels and risk of invasive breast cancer in premenopausal women. The magnitude of the association is similar to that observed in postmenopausal women - with an approximately two-fold higher risk in women in the top (versus bottom) $25 \%$ of hormone levels. Of note, the measurement of testosterone in premenopausal women is relatively straightforward given the consistent levels of this hormone across the menstrual cycle. The associations between estrogen and progesterone levels in premenopausal women and breast cancer risk have not been consistent, and further assessments are needed. The complexity of measuring estrogens in different phases of the menstrual cycle may have contributed to the inconsistencies in the literature. In the only study to detect a significant association with estradiol, follicular, but not luteal, levels were associated with risk; thus, further assessments stratified by menstrual cycle phase are needed. Most prior studies have not accounted in their analysis for menstrual cycle length in conjunction with the hormone measurement; evaluation of this additional aspect of the premenopausal hormone exposure could provide additional insights into these relationships. Data addressing the associations of estrogen metabolites with risk are particularly sparse, although with the development of new sensitive and specific assay methods, further studies should be completed in the near future. Thus, although the premenopausal hormonal milieu plays an important role in breast cancer etiology, evidence regarding circulating hormone levels is neither as plentiful nor as consistent as among postmenopausal women; hence, further research, with particular attention paid to menstrual cycle timing, is needed to elucidate these relationships.

Acknowledgments This study is supported by National Institutes of Health grant R01 CA67262.

\section{References}

1. Kaaks R, Rinaldi S, Key TJ, Berrino F, Peeters PH, Biessy C, Dossus L, Lukanova A, Bingham S, Khaw KT, Allen NE, Buenode-Mesquita HB, van Gils CH, Grobbee D, Boeing H, Lahmann $\mathrm{PH}$, Nagel G, Chang-Claude J, Clavel-Chapelon F, Fournier A, Thiebaut A, Gonzalez CA, Quiros JR, Tormo MJ, Ardanaz E, Amiano P, Krogh V, Palli D, Panico S, Tumino R, Vineis P, 
Trichopoulou A, Kalapothaki V, Trichopoulos D, Ferrari P, Norat T, Saracci R, Riboli E (2005) Postmenopausal serum androgens, oestrogens and breast cancer risk: the European prospective investigation into cancer and nutrition. Endocr Relat Cancer 12 (4):1071-1082

2. Missmer SA, Eliassen AH, Barbieri RL, Hankinson SE (2004) Endogenous estrogen, androgen, and progesterone concentrations and breast cancer risk among postmenopausal women. J Natl Cancer Inst 96(24):1856-1865

3. Endogenous Hormones and Breast Cancer Collaborative Group (2002) Endogenous sex hormones and breast cancer in postmenopausal women: reanalysis of nine prospective studies. J Natl Cancer Inst 94(8):606-616

4. Hankinson SE, Colditz GA, Willett WC (2004) Towards an integrated model for breast cancer etiology: the lifelong interplay of genes, lifestyle, and hormones. Breast Cancer Res 6(5):213-218

5. Liao DJ, Dickson RB (2002) Roles of androgens in the development, growth, and carcinogenesis of the mammary gland. J Steroid Biochem Mol Biol 80(2):175-189

6. Dickson RB, Stancel GM (2000) Estrogen receptor-mediated processes in normal and cancer cells. J Natl Cancer Inst Monogr 27:135-145

7. King RJ (1993) William L. McGuire memorial symposium. Estrogen and progestin effects in human breast carcinogenesis. Breast Cancer Res Treat 27(1-2):3-15

8. de Waard F, Thijssen JH (2005) Hormonal aspects in the causation of human breast cancer: epidemiological hypotheses reviewed, with special reference to nutritional status and first pregnancy. $\mathrm{J}$ Steroid Biochem Mol Biol 97(5):451-458

9. Cuzick J, Powles T, Veronesi U, Forbes J, Edwards R, Ashley S, Boyle P (2003) Overview of the main outcomes in breast-cancer prevention trials. Lancet 361(9354):296-300

10. Visvanathan K, Chlebowski RT, Hurley P, Col NF, Ropka M, Collyar D, Morrow M, Runowicz C, Pritchard KI, Hagerty K, Arun B, Garber J, Vogel VG, Wade JL, Brown P, Cuzick J, Kramer BS, Lippman SM (2009) American Society of Clinical Oncology Clinical Practice Guideline update on the use of pharmacologic interventions including tamoxifen, raloxifene, and aromatase inhibition for breast cancer risk reduction. J Clin Oncol 27(19):3235-3258, PMCID: PMC2716943

11. Rabaglio M, Aebi S, Castiglione-Gertsch M (2007) Controversies of adjuvant endocrine treatment for breast cancer and recommendations of the 2007 St Gallen conference. Lancet Oncol 8 (10):940-949

12. Muti P, Trevisan M, Micheli A, Krogh V, Bolelli G, Sciajno R, Berrino F (1996) Reliability of serum hormones in premenopausal and postmenopausal women over a one-year period. Cancer Epidemiol Biomarkers Prev 5(11):917-922

13. Micheli A, Muti P, Pisani P, Secreto G, Recchione C, Totis A, Fissi R, Cavalleri A, Panico S, Berrino F (1991) Repeated serum and urinary androgen measurements in premenopausal and postmenopausal women. J Clin Epidemiol 44(10):1055-1061

14. Missmer SA, Spiegelman D, Bertone-Johnson ER, Barbieri RL, Pollak MN, Hankinson SE (2006) Reproductibility of plasma hormone and growth factor levels among premenopausal women over a 2-3 year period. Cancer Epidemiol Biomarkers Prev 15 (5):972-978

15. Michaud DS, Manson JE, Spiegelman D, Barbieri RL, Sepkovic DW, Bradlow HL, Hankinson SE (1999) Reproducibility of plasma and urinary sex hormone levels in premenopausal women over a one-year period. Cancer Epidemiol Biomarkers Prev 8 (12):1059-1064

16. Willett WC (1998) Nutritional epidemiology, 2nd edn. Oxford University Press, New York

17. Rosner B, Spiegelman D, Willett WC (1992) Correction of logistic regression relative risk estimates and confidence intervals for random within-person measurement error. Am J Epidemiol 136(11):1400-1413

18. Mady EA, Ramadan EE, Ossman AA (2000) Sex steroid hormones in serum and tissue of benign and malignant breast tumor patients. Dis Markers 16(3-4):151-157

19. Lonning PE, Helle H, Duong NK, Ekse D, Aas T, Geisler J (2009) Tissue estradiol is selectively elevated in receptor positive breast cancers while tumour estrone is reduced independent of receptor status. J Steroid Biochem Mol Biol 117(1-3):31-41

20. Henderson BE, Feigelson HS (2000) Hormonal carcinogenesis. Carcinogenesis 21(3):427-433

21. Yager JD, Liehr JG (1996) Molecular mechanisms of estrogen carcinogenesis. Annu Rev Pharmacol Toxicol 36:203-232

22. Yager JD, Davidson NE (2006) Estrogen carcinogenesis in breast cancer. N Engl J Med 354(3):270-282

23. Van Aswegen CH, Purdy RH, Wittliff JL (1989) Binding of 2hydroxyestradiol and 4-hydroxyestradiol to estrogen receptors from human breast cancers. J Steroid Biochem 32(4):485-492

24. Anstead GM, Carlson KE, Katzenellenbogen JA (1997) The estradiol pharmacophore: ligand structure-estrogen receptor binding affinity relationships and a model for the receptor binding site. Steroids 62(3):268-303

25. Barnea ER, MacLusky NJ, Naftolin F (1983) Kinetics of catechol estrogen-estrogen receptor dissociation: a possible factor underlying differences in catechol estrogen biological activity. Steroids 41(5):643-656

26. Miyairi S, Ichikawa T, Nambara T (1991) Structure of the adduct of 16 alpha-hydroxyestrone with a primary amine: evidence for the Heyns rearrangement of steroidal D-ring alpha-hydroxyimines. Steroids 56(7):361-366

27. Bucala R, Fishman J, Cerami A (1982) Formation of covalent adducts between cortisol and 16 alpha-hydroxyestrone and protein: possible role in the pathogenesis of cortisol toxicity and systemic lupus erythematosus. Proc Natl Acad Sci USA 79 (10):3320-3324

28. Swaneck GE, Fishman J (1988) Covalent binding of the endogenous estrogen 16 alpha-hydroxyestrone to estradiol receptor in human breast cancer cells: characterization and intranuclear localization. Proc Natl Acad Sci USA 85(21):7831-7835

29. Lustig RH, Mobbs CV, Pfaff DW, Fishman J (1989) Temporal actions of 16 alpha-hydroxyestrone in the rat: comparisons of lordosis dynamics with other estrogen metabolites and between sexes. J Steroid Biochem 33(3):417-421

30. Seeger H, Wallwiener D, Kraemer E, Mueck AO (2005) Comparison of possible carcinogenic estradiol metabolites: effects on proliferation, apoptosis and metastasis of human breast cancer cells. Maturitas 54:72-77

31. Gupta M, McDougal A, Safe S (1998) Estrogenic and antiestrogenic activities of 16alpha- and 2-hydroxy metabolites of 17betaestradiol in MCF-7 and T47D human breast cancer cells. J Steroid Biochem Mol Biol 67(5-6):413-419

32. Schneider J, Huh MM, Bradlow HL, Fishman J (1984) Antiestrogen action of 2-hydroxyestrone on MCF-7 human breast cancer cells. J Biol Chem 259(8):4840-4845

33. Vandewalle B, Lefebvre J (1989) Opposite effects of estrogen and catecholestrogen on hormone-sensitive breast cancer cell growth and differentiation. Mol Cell Endocrinol 61(2):239-246

34. Mueck AO, Seeger H, Lippert TH (2002) Estradiol metabolism and malignant disease. Maturitas 43(1):1-10

35. Cavalieri EL, Stack DE, Devanesan PD, Todorovic R, Dwivedy I, Higginbotham S, Johansson SL, Patil KD, Gross ML, Gooden JK, Ramanathan R, Cerny RL, Rogan EG (1997) Molecular origin of cancer: catechol estrogen-3, 4-quinones as endogenous tumor initiators. Proc Natl Acad Sci USA 94(20):10937-10942

36. Stack DE, Byun J, Gross ML, Rogan EG, Cavalieri EL (1996) Molecular characteristics of catechol estrogen quinones in 
reactions with deoxyribonucleosides. Chem Res Toxicol 9 (5):851-859

37. Yue W, Santen RJ, Wang JP, Li Y, Verderame MF, Bocchinfuso WP, Korach KS, Devanesan P, Todorovic R, Rogan EG, Cavalieri EL (2003) Genotoxic metabolites of estradiol in breast: potential mechanism of estradiol induced carcinogenesis. J Steroid Biochem Mol Biol 86(3-5):477-486

38. Devanesan P, Todorovic R, Zhao J, Gross ML, Rogan EG, Cavalieri EL (2001) Catechol estrogen conjugates and DNA adducts in the kidney of male Syrian golden hamsters treated with 4-hydroxyestradiol: potential biomarkers for estrogen-initiated cancer. Carcinogenesis 22(3):489-497

39. Chakravarti D, Mailander PC, Li KM, Higginbotham S, Zhang HL, Gross ML, Meza JL, Cavalieri EL, Rogan EG (2001) Evidence that a burst of DNA depurination in SENCAR mouse skin induces error-prone repair and forms mutations in the H-ras gene. Oncogene 20(55):7945-7953

40. Cavalieri EL, Kumar S, Todorovic R, Higginbotham S, Badawi AF, Rogan EG (2001) Imbalance of estrogen homeostasis in kidney and liver of hamsters treated with estradiol: implications for estrogen-induced initiation of renal tumors. Chem Res Toxicol 14(8):1041-1050

41. Wysowski DK, Comstock GW, Helsing KJ, Lau HL (1987) Sex hormone levels in serum in relation to the development of breast cancer. Am J Epidemiol 125(5):791-799

42. Helzlsouer KJ, Alberg AJ, Bush TL, Longcope C, Gordon GB, Comstock GW (1994) A prospective study of endogenous hormones and breast cancer. Cancer Detect Prev 18(2):79-85

43. Kabuto M, Akiba S, Stevens RG, Neriishi K, Land CE (2000) A prospective study of estradiol and breast cancer in Japanese women. Cancer Epidemiol Biomarkers Prev 9(6):575-579

44. Thomas HV, Key TJ, Allen DS, Moore JW, Dowsett M, Fentiman IS, Wang DY (1997) A prospective study of endogenous serum hormone concentrations and breast cancer risk in premenopausal women on the island of Guernsey. Br J Cancer 75(7):1075-1079

45. Rosenberg CR, Pasternack BS, Shore RE, Koenig KL, Toniolo PG (1994) Premenopausal estradiol levels and the risk of breast cancer: a new method of controlling for day of the menstrual cycle. Am J Epidemiol 140(6):518-525

46. Kaaks R, Berrino F, Key T, Rinaldi S, Dossus L, Biessy C, Secreto G, Amiano P, Bingham S, Boeing H, Bueno de Mesquita HB, Chang-Claude J, Clavel-Chapelon F, Fournier A, van Gils $\mathrm{CH}$, Gonzalez CA, Gurrea AB, Critselis E, Khaw KT, Krogh V, Lahmann PH, Nagel G, Olsen A, Onland-Moret NC, Overvad K, Palli D, Panico S, Peeters P, Quiros JR, Roddam A, Thiebaut A, Tjonneland A, Chirlaque MD, Trichopoulou A, Trichopoulos D, Tumino R, Vineis P, Norat T, Ferrari P, Slimani N, Riboli E (2005) Serum sex steroids in premenopausal women and breast cancer risk within the European Prospective Investigation into Cancer and Nutrition (EPIC). J Natl Cancer Inst 97(10):755-765

47. Eliassen AH, Missmer SA, Tworoger SS, Spiegelman D, Barbieri RL, Dowsett M, Hankinson SE (2006) Endogenous steroid hormone concentrations and risk of breast cancer among premenopausal women. J Natl Cancer Inst 98(19):1406-1415

48. Siiteri PK (1981) Extraglandular oestrogen formation and serum binding of oestradiol: relationship to cancer. J Endocrinol 89 (Suppl):119P-129P

49. Siiteri PK, MacDonald PC (1973) The role of extraglandular estrogen in human endocrinology. In: Geiger SR, Astwood EB, Greep RO (eds) Handbook of physiology: section 7Endocrinology 615-629. American Physiological Society, New York

50. Santoro N, Lasley B, McConnell D, Allsworth J, Crawford S, Gold EB, Finkelstein JS, Greendale GA, Kelsey J, Korenman S, Luborsky JL, Matthews K, Midgley R, Powell L, Sabatine J, Schocken M, Sowers MF, Weiss G (2004) Body size and ethnicity are associated with menstrual cycle alterations in women in the early menopausal transition: the Study of Women's Health across the Nation (SWAN) Daily Hormone Study. J Clin Endocrinol Metab 89(6):2622-2631

51. Landgren BM, Collins A, Csemiczky G, Burger HG, Baksheev L, Robertson DM (2004) Menopause transition: annual changes in serum hormonal patterns over the menstrual cycle in women during a nine-year period prior to menopause. J Clin Endocrinol Metab 89(6):2763-2769

52. Yue W, Santner SJ, Masamura S, Wang JP, Demers LM, Hamilton C, Santen RJ (1998) Determinants of tissue estradiol levels and biologic responsiveness in breast tumors. Breast Cancer Res Treat 49(Suppl 1):S1-S7, discussion S33-7

53. Masamura S, Santner SJ, Gimotty P, George J, Santen RJ (1997) Mechanism for maintenance of high breast tumor estradiol concentrations in the absence of ovarian function: role of very high affinity tissue uptake. Breast Cancer Res Treat 42(3):215226

54. Stute P, Wood CE, Kaplan JR, Cline JM (2004) Cyclic changes in the mammary gland of cynomolgus macaques. Fertil Steril 82 (Suppl 3):1160-1170

55. Meilahn EN, De Stavola B, Allen DS, Fentiman I, Bradlow HL, Sepkovic DW, Kuller LH (1998) Do urinary oestrogen metabolites predict breast cancer? Guernsey III cohort follow-up. Br J Cancer 78(9):1250-1255

56. Muti P, Bradlow HL, Micheli A, Krogh V, Freudenheim JL, Schunemann HJ, Stanulla M, Yang J, Sepkovic DW, Trevisan M, Berrino F (2000) Estrogen metabolism and risk of breast cancer: a prospective study of the 2:16 alpha-hydroxyestrone ratio in premenopausal and postmenopausal women. Epidemiology 11 (6):635-640

57. Arslan AA, Shore RE, Afanasyeva Y, Koenig KL, Toniolo P, Zeleniuch-Jacquotte A (2009) Circulating estrogen metabolites and risk for breast cancer in premenopausal women. Cancer Epidemiol Biomarkers Prev 18(8):2273-2279

58. Xu X, Veenstra TD, Fox SD, Roman JM, Issaq HJ, Falk R, Saavedra JE, Keefer LK, Ziegler RG (2005) Measuring fifteen endogenous estrogens simultaneously in human urine by highperformance liquid chromatography-mass spectrometry. Anal Chem 77(20):6646-6654

59. Falk RT, Xu X, Keefer L, Veenstra TD, Ziegler RG (2008) A liquid chromatography-mass spectrometry method for the simultaneous measurement of 15 urinary estrogens and estrogen metabolites: assay reproducibility and interindividual variability. Cancer Epidemiol Biomarkers Prev 17(12):3411-3418

60. Eliassen HA, Ziegler RG, Rosner B, Veenstra TD, Roman JM, Xu X, Hankinson SE (2009) Reproducibility of fifteen urinary estrogens and estrogen metabolites over a 2- to 3-year period in premenopausal women. Cancer Epidemiol Biomarkers Prev 18(11):2860

61. Ebeling P, Koivisto VA (1994) Physiological importance of dehydroepiandrosterone. Lancet 343(8911):1479-1481

62. Seymour-Munn K, Adams J (1983) Estrogenic effects of 5androstene-3 beta, 17 beta-diol at physiological concentrations and its possible implication in the etiology of breast cancer. Endocrinology 112(2):486-491

63. Micheli A, Muti P, Secreto G, Krogh V, Meneghini E, Venturelli E, Sieri S, Pala V, Berrino F (2004) Endogenous sex hormones and subsequent breast cancer in premenopausal women. Int $\mathrm{J}$ Cancer 112(2):312-318

64. Zeleniuch-Jacquotte A, Shore RE, Koenig KL, Akhmedkhanov A, Afanasyeva Y, Kato I, Kim MY, Rinaldi S, Kaaks R, Toniolo P (2004) Postmenopausal levels of oestrogen, androgen, and SHBG and breast cancer: long-term results of a prospective study. Br J Cancer 90(1):153-159

65. Helzlsouer KJ, Gordon GB, Alberg AJ, Bush TL, Comstock GW (1992) Relationship of prediagnostic serum levels of dehydroe- 
piandrosterone and dehydroepiandrosterone sulfate to the risk of developing premenopausal breast cancer. Cancer Res 52(1):1-4

66. Page JH, Colditz GA, Rifai N, Barbieri RL, Willett WC, Hankinson SE (2004) Plasma adrenal androgens and risk of breast cancer in premenopausal women. Cancer Epidemiol Biomarkers Prev 13(6):1032-1036

67. Tworoger SS, Missmer SA, Eliassen AH, Spiegelman D, Folkerd E, Dowsett M, Barbieri RL, Hankinson SE (2006) The association of plasma DHEA and DHEA sulfate with breast cancer risk in predominantly premenopausal women. Cancer Epidemiol Biomarkers Prev 15(5):967-971

68. Mauvais-Jarvis P, Kuttenn F, Gompel A (1987) Antiestrogen action of progesterone in breast tissue. Horm Res 28(2-4):212-218

69. Doisneau-Sixou SF, Sergio CM, Carroll JS, Hui R, Musgrove EA, Sutherland RL (2003) Estrogen and antiestrogen regulation of cell cycle progression in breast cancer cells. Endocr Relat Cancer 10 (2):179-186

70. Pike MC, Spicer DV, Dahmoush L, Press MF (1993) Estrogens, progestogens, normal breast cell proliferation, and breast cancer risk. Epidemiol Rev 15(1):17-35

71. Lanari C, Molinolo AA (2002) Progesterone receptors-animal models and cell signalling in breast cancer. Diverse activation pathways for the progesterone receptor: possible implications for breast biology and cancer. Breast Cancer Res 4(6):240-243

72. Campagnoli C, Clavel-Chapelon F, Kaaks R, Peris C, Berrino F (2005) Progestins and progesterone in hormone replacement therapy and the risk of breast cancer. J Steroid Biochem Mol Biol 96(2):95-108
73. Collaborative Group on Hormonal Factors in Breast Cancer (1997) Breast cancer and hormone replacement therapy: collaborative reanalysis of data from 51 epidemiological studies of 52 , 705 women with breast cancer and 108, 411 women without breast cancer. Lancet 350(9084):1047-1059

74. Chen WY, Hankinson SE, Schnitt SJ, Rosner BA, Holmes MD, Colditz GA (2004) Association of hormone replacement therapy to estrogen and progesterone receptor status in invasive breast carcinoma. Cancer 101(7):1490-1500

75. Anderson GL, Limacher M, Assaf AR, Bassford T, Beresford SA, Black H, Bonds D, Brunner R, Brzyski R, Caan B, Chlebowski R, Curb D, Gass M, Hays J, Heiss G, Hendrix S, Howard BV, Hsia J, Hubbell A, Jackson R, Johnson KC, Judd H, Kotchen JM, Kuller L, LaCroix AZ, Lane D, Langer RD, Lasser N, Lewis CE, Manson J, Margolis K, Ockene J, O'Sullivan MJ, Phillips L, Prentice RL, Ritenbaugh C, Robbins J, Rossouw JE, Sarto G, Stefanick ML, Van Horn L, Wactawski-Wende J, Wallace R, Wassertheil-Smoller S (2004) Effects of conjugated equine estrogen in postmenopausal women with hysterectomy: the Women's Health Initiative randomized controlled trial. JAMA 291(14):1701-1712

76. Chlebowski RT, Hendrix SL, Langer RD, Stefanick ML, Gass M, Lane D, Rodabough RJ, Gilligan MA, Cyr MG, Thomson CA, Khandekar J, Petrovitch H, McTiernan A (2003) Influence of estrogen plus progestin on breast cancer and mammography in healthy postmenopausal women: the Women's Health Initiative randomized trial. JAMA 289(24):32433253 